\title{
Knowledge Regarding Prevention of Atherosclerosis Among Young Adults
}

\author{
${ }^{1}$ Y Prabhukumar \\ Associate Professor \\ Department of Medical surgical nursing \\ College of Nursing, Bangalore Baptist hospital
}

\author{
${ }^{2}$ Subhashini \\ $4^{\text {th }}$ year, B.Sc Nursing \\ College of Nursing, Bangalore Baptist hospital
}

\begin{abstract}
\section{$>$ Introduction}

Atherosclerosis is responsible for $\mathbf{5 0 \%}$ of all death in Weston societies and it is a chronic inflammatory disease of arteries ${ }^{1}$. Heart attacks, stroke and peripheral arterial diseases are developed by atherosclerotic diseases. The incidence is difficult to measure accurately due to its asymptomatic condition. Over 370,000 death occurs annually due to coronary heart disease in the modernized society. Men over 45 years are more predominant to develop plague rupture and it contributes $75 \%$ of myocardial infarctions ${ }^{1} .90 \%$ cardiovascular disease related death can be prevented by lifestyle changes.
\end{abstract}

\section{$>$ Methods}

A descriptive study was conducted to evaluate the knowledge of younger adults on prevention of atherosclerosis in outpatient department, Baptist hospital, Bangalore. Hundred voluntaries are enrolled to the study and prior consent was taken.

\section{Results}

The mean age of the study participant are $29.4 \pm$ 5.2 years and $53.0 \%$ were males and $47.0 \%$ were females. $34.0 \%$ are graduates. In the regards to level of knowledge it was classified as adequate, moderate and Inadequate and the result is $27.0 \%, \mathbf{5 6 . 0 \%}$ and $\mathbf{1 7 . 0 \%}$ respectively. The chi-square value of $\chi^{2}=4.29(p=0.116)$ between Educational status and level of knowledge and $\chi^{2}=4.76(p=0.092)$ between gender and level of knowledge shows, there is no statistically significant associations. Pearson correlation coefficient was calculated for age and income with knowledge. The $\mathbf{r}=$ $0.08(p=0.434)$ of age and knowledge, $r=-0.05(p=0.632)$ of income and knowledge both shows negligible correlation with no significance.

\section{Conclusion}

This study concludes that the knowledge on prevention of atherosclerosis among young adults are moderate and there is no relationship was observed with knowledge and educational status, gender, age and income. This result may suggest to have awareness programme on prevention of atherosclerosis among young adults to improve their lifestyle by enhancing the knowledge.

Keywords:- Athrosclerosis, Younger Adults, Cardiovascular Disease, Knowledge On Prevention.

\section{INTRODUCTION}

Atherosclerosis is responsible for $50 \%$ of all death in Weston societies and it is a chronic inflammatory disease of arteries $^{1}$. Heart attacks, stroke and peripheral arterial diseases are developed by atherosclerotic diseases. The incidence is difficult to measure accurately due to its asymptomatic condition. Over 370,000 death occurs annually due to coronary heart disease in the modernized society. Men over 45 years are more predominant to develop plague rupture and it contributes $75 \%$ of myocardial infarctions ${ }^{1} .90 \%$ cardiovascular disease related death can be prevented by lifestyle changes.

In India Cardiovascular diseases (CVD) are leading cause for the death. One fourth of deaths are due to CVD. More than $80 \%$ of CVD death occurs due to Ischemic heart disease and stroke. As per The Global Burden of Disease estimation the age standardized CVD deaths in India are 272/100 000 population which is comparatively higher than the global burden of 235/ 100000 population. Premature mortality rate in India increased by $59 \%$, from 23.2 million (1990) to 37 million (2010). Constant raise in epidemic suggests the development of new strategies includes evidence based practices, reinforcement of health system, emphasis of health awareness, early detection, treatment with newer technologies and innovations which may reduce and prevent the disease burden.

Lori Mosca et.l conducted a study on Awareness, Perception, and Knowledge of Heart Disease Risk and Prevention Among Women in the United States the result shows that the Women aged 25 to 44 years were not well informed about their heart diseaseand stroke by their physicians. Among them, $90 \%$ are like to discuss about their heart disease or risk reduction with their physicians however $70 \%$ of them are not discussing about their problems ${ }^{4}$. 


\section{MATERIALS AND METHODS}

A descriptive study was conducted to evaluate the knowledge of younger adults on prevention of atherosclerosis in outpatient department, Baptist hospital, Bangalore. Hundred voluntaries are enrolled to the study and prior consent was taken. Knowledge was assessed with structured questionnaire by interview. The data was collected and entered in Microsoft Excel v.2013 and it was analyzed using Epi Info 7.

\section{RESULTS}

The analyzed data was tabulated, interpreted and presented as follow:

\begin{tabular}{|c|c|c|}
\hline S.No & Variable & Percentage $(\%)$ \\
\hline \multirow[t]{3}{*}{1} & \multicolumn{2}{|c|}{ Gender } \\
\hline & Male & 47 \\
\hline & Female & 53 \\
\hline \multirow[t]{3}{*}{2} & \multicolumn{2}{|c|}{ Dietary Pattern } \\
\hline & Vegetarian & 10 \\
\hline & Non - vegetarian & 90 \\
\hline \multirow[t]{6}{*}{3} & \multicolumn{2}{|c|}{ Educational qualification } \\
\hline & Primary & 11 \\
\hline & Secondary & 17 \\
\hline & Diploma & 31 \\
\hline & Graduate & 34 \\
\hline & Post graduate & 7 \\
\hline \multirow[t]{5}{*}{4} & \multicolumn{2}{|c|}{ Religion } \\
\hline & Hindu & 71 \\
\hline & Muslim & 11 \\
\hline & Christian & 16 \\
\hline & Sikh & 2 \\
\hline
\end{tabular}

Table 1:- Demographic Profile of young adults $(\mathrm{N}=100)$

The above table shows that $53.0 \%$ were males and $47.0 \%$ were females, $34.0 \%$ are graduates, $90 \%$ were non-vegetarians and $71 \%$ were Hindu's.

\section{Level of knowledge on prevention of atherosclerosis}

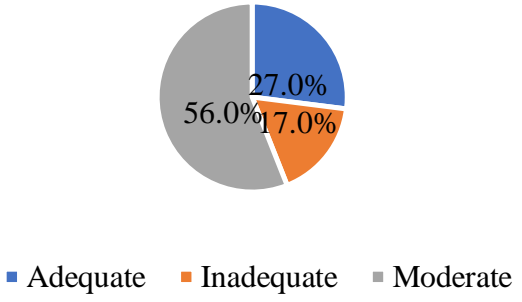

Fig 1:- Level of knowledge on prevention of atherosclerosis among young adults

Above figure shows that $56.0 \%$ of the had moderate knowledge, $27.0 \%$ of them had adequate knowledge and $17.0 \%$ of them had inadequate knowledge.

\begin{tabular}{|c|c|c|c|c|c|c|}
\hline \multirow{2}{*}{ S.No } & \multirow{2}{*}{ Demographic variable } & \multicolumn{3}{|c|}{ Level of knowledge } & \multirow{2}{*}{ Chi-square } & \multirow{2}{*}{ p-Value } \\
\hline & & Adequate & Moderate & Inadequate & & \\
\hline \multirow[t]{3}{*}{1} & \multicolumn{6}{|c|}{ Educational qualification } \\
\hline & Schooling & 8 & 12 & 8 & \multirow{2}{*}{4.29} & \multirow{2}{*}{0.116} \\
\hline & Higher degree & 19 & 44 & 9 & & \\
\hline \multirow[t]{3}{*}{2} & \multicolumn{6}{|c|}{ Gender } \\
\hline & Male & 12 & 28 & 13 & \multirow{2}{*}{4.76} & \multirow{2}{*}{0.092} \\
\hline & Female & 15 & 28 & 4 & & \\
\hline
\end{tabular}

Table 2:- Association between level of knowledge with selected demographic variables 
The above table shows that the chi-square value of $\chi^{2}$ $=4.29(\mathrm{p}=0.116)$ between Educational status and level of knowledge and $\chi^{2}=4.76(\mathrm{p}=0.092)$ between gender and level of knowledge shows, there is no statistically significant associations.

\section{Correlation between age and}

$$
r=0.08(p=0.434)
$$

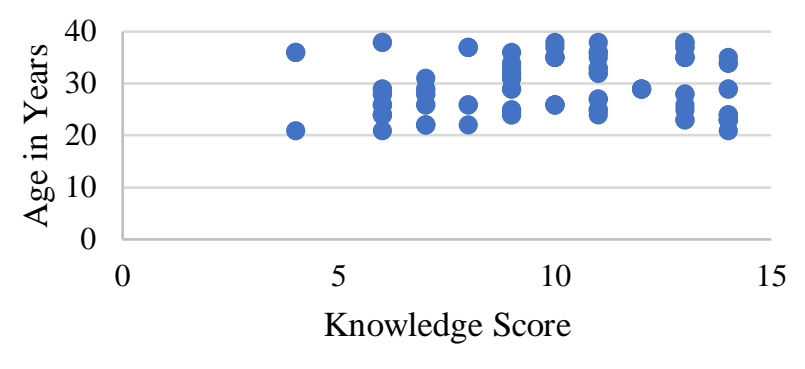

Fig 2:- Correlation between age and knowledge on prevention of atherosclerosis among young adults

The Pearson correlation between age and knowledge $r$ $=0.08(\mathrm{p}=0.434)$ shows the positive negligible correlation with no statistical significance.

\section{Correlation between income and knowledge$$
\mathrm{r}=-0.05(\mathrm{p}=0.632)
$$

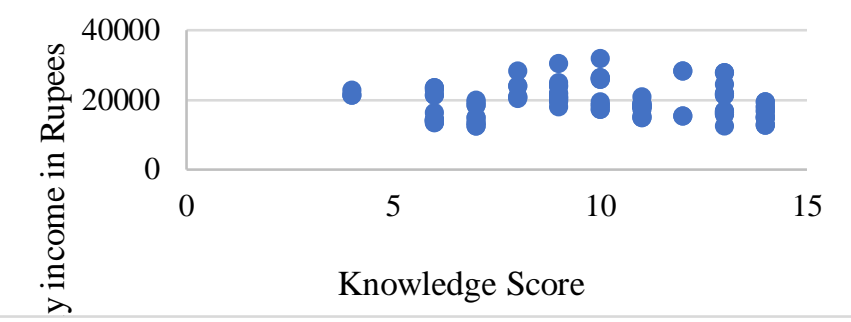

Fig 3:- Correlation between monthly income and knowledge on prevention of atherosclerosis among young adults

The Pearson correlation between monthly income and knowledge $r=-0.05 \quad(p=0.632)$ shows the negative negligible correlation with no statistical significance.

\section{CONCLUSION}

This study concludes that the knowledge on prevention of atherosclerosis among young adults are moderate and there is no relationship was observed with knowledge and educational status, gender, age and income. This result may suggest to have awareness programme on prevention of atherosclerosis among young adults to improve their lifestyle by enhancing the knowledge.

\section{ACKNOWLEDGMENT}

I acknowledge the management of Baptist hospital, Bangalore and Principal of College of nursing, Bangalore Baptist for their constant support throughout the study period.

\section{REFERENCES}

[1]. Pahwa R, Jialal I. Atherosclerosis [Internet]. Ncbi.nlm.nih.gov. 2020. Available from: https://www.ncbi.nlm.nih.gov/books/NBK507799/

[2]. Prabhakaran D, Jeemon P, Roy A. Cardiovascular Diseases in India | Circulation [Internet]. Ahajournals.org. 2020. Available from: https://www.ahajournals.org/doi/10.1161/CIRCULATI ONAHA.114.008729

[3]. Hirsch A, Murphy T, Lovell M, Twillman G, TreatJacobson D, Harwood E et al. Gaps in Public Knowledge of Peripheral Arterial Disease. Circulation. 2007;116(18):2086-2094.

[4]. Mosca L. Awareness, Perception, and Knowledge of Heart Disease Risk and Prevention Among Women in the United States. Archives of Family Medicine. 2000;9(6):506-515.

[5]. Castaldo J, Nester J, Wasser T, Masiado T, Rossi M, Young $M$ et al. Physician Attitudes Regarding Cardiovascular Risk Reduction: The Gaps Between Clinical Importance, Knowledge, and Effectiveness. Disease Management. 2005;8(2):93-105.

[6]. V V, R G. Awareness and risk factors of atherosclerosis among working professionals -- A survey. Drug Invention Today. 2020;14(3):462-466.

[7]. Okunrintemi V, Valero-Elizondo J, Patrick B, Salami J, Tibuakuu M, Ahmad S et al. Gender Differences in Patient-Reported Outcomes Among Adults With Atherosclerotic Cardiovascular Disease. Journal of the American Heart Association. 2018;7(24). 